\title{
Ensayo
}

\section{La cultura pop en el pensamiento de Sergio Roncallo-Dow: el sur es el mensaje}

\author{
Enrique Uribe-Jongbloed ${ }^{1}$ \\ Daniel Aguilar-Rodríguez ${ }^{2}$ \\ Hernán D. Espinosa-Medina ${ }^{3}$
}

DOI: $10.5294 /$ pacla.2020.23.s.2

\section{Para citar este ensayo / to reference this essay / para citar este ensaio}

Uribe-Jongbloed, E., Aguilar-Rodríguez, D. y Espinosa-Medina, H. D. (2020). La cultura pop en el pensamiento de Sergio Roncallo-Dow: el sur es el mensaje. Palabra Clave, 23(supl.), e23s2. https://doi.org/10.5294/pacla.2020.23.s.2

\section{Resumen}

Este ensayo busca evidenciar la relevancia que ha tenido la cultura pop en la amplia obra y fabulosa vida de Sergio Roncallo-Dow. Esta travesía nos lleva a vincular conceptos como el de habitar, el dasein y el mit-dasein de Heidegger, con el sensorium de Walter Benjamin, a través de la máxima de Marshall McLuhan, el medio es el mensaje. Se presentan tres campos de la vida y obra de Sergio que se entrelazan para dar cuenta de su aproximación al apotegma mcluhaniano. Este camino aborda la televisión en Colombia en la década de los ochenta, la escena de la música rock de la cual Sergio fue parte y su relación con los videojuegos y YouTube. Esta exploración nos permite ver algunas de sus sondas principales, su crítica a los modelos binarios y a la separación de la cultura popular y de élite, la centralidad de la imbricación entre técnica y cultura, y su propuesta de la comprensión de nuestra hibri-

\footnotetext{
1 https://orcid.org/0000-0002-9415-7628. Universidad Externado de Colombia, Colombia. enrique.uribe@uexternado.edu.co

2 https://orcid.org/0000-0002-2112-2504. Universidad Externado de Colombia, Colombia. daniel.aguilar@uexternado.edu.co

3 https://orcid.org/0000-0002-3561-4016. Universidad de La Sabana, Colombia. hernanem@unisabana.edu.co
} 
dación latinoamericana como nuestro punto de partida para entender-nos en la comunicación.

\section{Palabras clave}

Sergio Roncallo-Dow; Marshall McLuhan; hibridación; cultura pop; sondas. 
Life's like a mayonnaise soda And life's like space without room And life's like bacon and ice cream That's what life's like without you What's Good, Lou Reed (1992)

Sergio $^{4}$ era ante todo un provocador. Disparando ideas a modo de sondas, como aquellas que lanzaba su maestro Marshall McLuhan (Roncallo-Dow, 2011b), Sergio buscaba explorar ideas, expandir nociones y, ante todo, compartir perspectivas. Este ensayo surge, precisamente, de varias ideas con las que Sergio buscó exhortarnos. Algunas de estas nociones las pudimos avanzar y discutir con él, otras se quedaron en el papel o en el tintero. ${ }^{5}$ En particular, ahondamos en su abordaje de la cultura popular. No la asumimos como una categoría marxista de contraposición a la cultura de élite, ni como una forma localizada espacial e históricamente, como se aborda en los estudios culturales, sino como aquella relación constante y negociación perpetua entre los medios y nuestra vida cotidiana.

Sergio (Roncallo-Dow, 2014a) se basó en el concepto heideggeriano de habitar (wohnen) para expresar de manera más profunda la noción mcluhaniana de entorno. Esta idea la utilizó para aclarar que una dimensión "ecológica de los medios mcluhanianos supone comprender que los alcances del sistema técnico son lo suficientemente amplios para sostener la idea de un habitar, a su vez, técnicamente configurado" (p. 114).

En ese texto, Sergio (Roncallo-Dow, 2014a) buscaba aclarar la relevancia de comprender, no solo los medios de comunicación, sino todos los medios mcluhanianos (por ejemplo, el dinero, ${ }^{6}$ el automóvil, la ropa, etc.) mencionados en Comprender los medios de comunicación: las extensiones del ser humano (McLuhan, 1994) como un proceso de existencia e interrelación con ellos, que cambian la forma en que entendemos y en que habitamos el mundo.

\footnotetext{
4 Aquí nos tomaremos una licencia de la escritura académica y nos referiremos a Sergio por su nombre que no por su apellido. La referencia a sus textos aparecerá siempre entre paréntesis, como lo determina el estilo APA 7a edición.

5 Realmente se quedaron en un archivo digital de procesador de texto en algún disco duro de algún computador, pero la recurrente metáfora escritural pre-digital sigue siendo hermosa.

6 Para este tema en particular, se puede leer Roncallo-Dow y Uribe-Jongbloed (2017a).
} 
Por eso, sus disquisiciones no se centraban en la especificidad de los contenidos de algunos medios de comunicación, salvo para usarlos de ejemplo de características más profundas que ya habían reconfigurado la relación de las personas con su entorno. Así, expandió e hizo suyo el aforismo mcluhaniano "el medio es el mensaje", con el que destaca que no es la cantidad de contenidos específicos de cada medio la que altera y define el mundo que vivimos, sino su omnipresencia y la forma en que reconfiguran la capacidad técnica y poiética humana.

Muchas veces, Sergio utilizaba elementos de la cultura popular para ilustrar estos grandes cambios en la forma en que los humanos interactuamos con nuestro entorno. Sergio (Roncallo-Dow, 2011a) entendía la cultura como anclada en el proceso tecno-lógico de doble poiésis del acto técnico que involucra su comprensión y denominación. Es decir, una acción que podríamos denominar técnica por cuanto repetible con iguales resultados - golpear un objeto para producir un sonido, por ejemplo- se convierte en una reflexión tecno-lógica cuando tratamos de comprender la relación del impacto con el sonido. Así, le damos — y creamos de paso- el sentido a la palabra música y generamos la doble poiésis. Uno puede repetir la técnica y obtener el mismo resultado original, pero una tecno-logía surge al transformar esa técnica a través de la creación de conocimiento, nombrando y estructurando una serie de relaciones alrededor suyo que nos permiten ir más allá de una reproducción constante de la técnica misma.

Visto así,

la cultura se constituye en algo técnico en la medida que engrana de modo decisivo la idea misma de mundo que se des-vela en la tecnicidad; por esto resulta complicado pretender, hoy por hoy, continuar la reflexión sobre lo técnico pasando por alto el hecho mismo de que, si bien el hombre en el amanecer tuvo piedras, hoy tiene [nuevas herramientas]. (p. 57)

Lo cultural es, entonces, el proceso mismo de doble poiésis en el cual al ejercicio de reflexión (lógos) de la técnica (téchnē) le damos sentido y nombre.

La cultura popular vendría siendo, para Sergio, la forma en la que hemos desarrollado ese proceso tecno-lógico de entender la técnica y de dar- 
le un sentido y una forma de descripción, desde un entorno amplio que no distingue entre una cultura con $\mathrm{C}$ mayúscula - una cultura de élitey otra del resto de la población. En esa idea, seguía fielmente a su mentor, Marshall McLuhan (2015), quien afirma:

La muy arraigada convención de que la cultura se filtra de las élites para llegar a los niveles populares no resiste ni por un instante el examen de los hechos de la historia de la lengua o la formación lingüística. [...] Hoy, esta cándida visión de la cultura, orientada puramente al contenido, nos impide prestarles atención de un modo directo, serio y crítico a los medios de comunicación, viejos y nuevos, como formas artísticas. (pp. 281-282)

Por esta razón, Sergio (Roncallo-Dow et al., 2016) se refugiaba constantemente en los pensamientos de Benjamin (1989) para evidenciar que, contrario a lo discutido usualmente, en todos estos desarrollos tecnológicos que devenían en medios de comunicación podría existir el aura perdida. Es decir, que ese espíritu profundo del arte que Benjamin consideraba se había desvanecido con la reproductibilidad técnica podía existir de nuevo a través de una plataforma como YouTube (RoncalloDow et al., 2016, pp. 95-120). En cierto sentido, Sergio (Roncallo-Dow y Otero Herrera, 2016) consideraba que el consumo masivo a partir de la industria cultural se debe a que "es precisamente el reflejo de nuestra condición imperfecta el que nos hace abocarnos al consumo de fantasmagorías como Supermán" (p. 266).

Nuestra imperfección, ese vacío ontológico de nuestro ser que clama por ser llenado, encontraba, para Sergio, un puente a su propia experiencia en la nostalgia. Quizá era su afición por las figuras coleccionables lo que llevaba a Sergio (Uribe-Jongbloed y Roncallo-Dow, 2018) a reflejar su experiencia de la cultura popular en su entorno personal, planteando que

la continua analepsis de la cultura popular responde, precisamente, a aquel fetichismo sobre el pasado que es re-descubierto a través de otros ojos y que les otorga a aquellos años [pasados] un halo de pureza e inocencia que nunca hubiésemos percibido entonces. La cultura popular construye sobre esta idea de nostalgia en el sentido 
en que se convierte en un caldo de cultivo para la re-mezcla del pasa-

do con las posibilidades del presente. (p. 52) ${ }^{7}$

Siendo así, nuestro viaje por la cultura popular, aquí presente, es un viaje por recuperar nuestra seguridad ontológica, bien más que preciado por Sergio en sus interacciones personales y en sus charlas como profesor. Nuestro escape hacia el pasado busca retornar a una felicidad y tranquilidad perdidas, un universo común que nos construye hacia el presente, y que nos indica cuál fue nuestro entorno mediático, aquel en el que navegamos con tranquilidad. Lo que ofrecemos a continuación son las varias avenidas que Sergio inspiró, las exploraciones que surgieron con él en nuestros diversos trabajos conjuntos o en las veladas que nos compartió, y que buscan señalar los caminos que Sergio dejó para que exploráremos.

\section{La nostalgia televisiva de la década de los ochenta}

En escala del uno al diez, piensa en mí como... once

Automan

El afiche de Alf en el estudio (figura 1) donde Sergio pasaba largas horas leyendo, escribiendo, haciendo música y departiendo con amigos es una minúscula muestra de su gusto por coleccionar memorabilia ochentera. Figuras de acción de Los magníficos, Tortugas Ninja, Robocop, una máscara del presentador Jota Mario Valencia y camisetas autodiseñadas de las telenovelas Caballo viejo y Calamar eran muestras de su aprecio por la televisión nacional e internacional que forjó gran parte de su infancia.

Esa televisión que fuese su fascinación y cuyo valor había compartido con, y claramente se había visto influido por, otro de sus mentores, Jesús Martín-Barbero. Es precisamente Martín-Barbero (2010) quien nos planteaba lo relevante de esa cultura que surge en la televisión, en su mezcla en-

7 Esta, como todas las traducciones de las obras de Sergio que se encuentran en inglés, es una des-traducción. Gran parte de los textos en inglés los trabajamos en conjunto, y su traducción al inglés usualmente llegaba en una etapa final, por lo que conservamos versiones de borrador en español de muchos de sus textos que han sido utilizadas para las citas aquí planteadas.

6 La cultura pop en el pensamiento de Sergio Roncallo-Dow: el sur es el mensaje - Enrique Uribe-Jongbloed y otros 


\section{Figura 1. El aprecio por la cultura pop en el estudio de Sergio.}

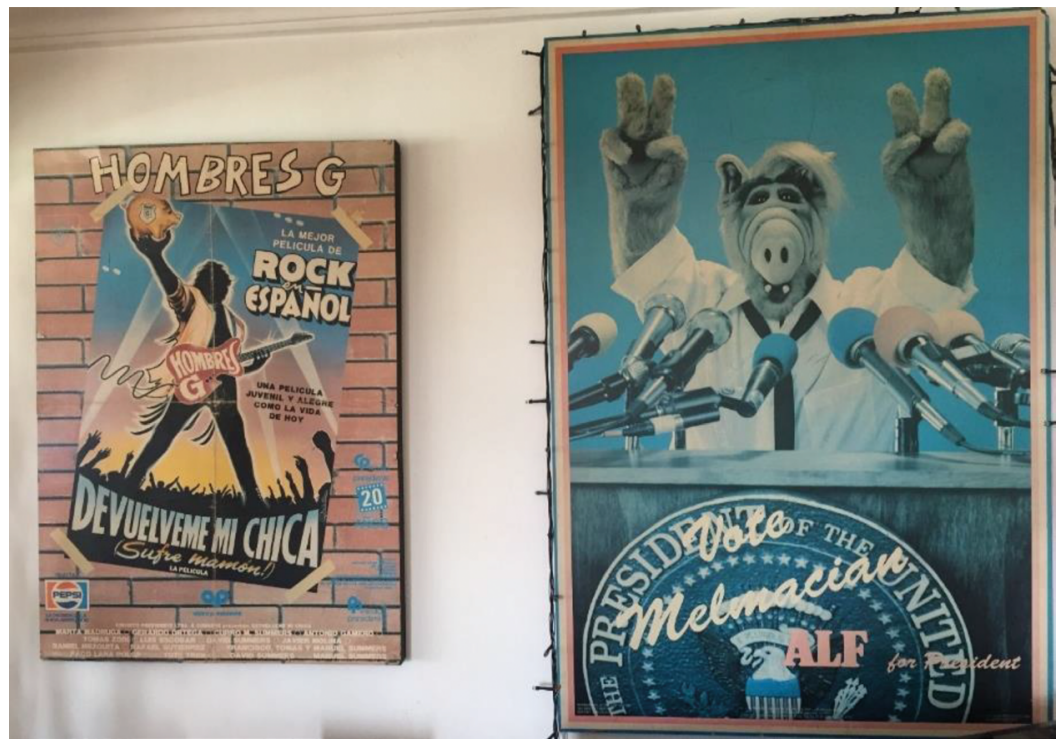

Fuente: Sergio Roncallo-Dow, archivo personal.

tre lo popular y lo masivo, entre los debates de culturalistas que denigraban de la televisión y los comerciantes que la presentaban como respuesta a la demanda de las necesidades de la gente. Señalaba Martín-Barbero:

Los mandarines de la cultura seguirán preguntándose si acaso la televisión puede ser considerada cultura mientras, nos guste o no y para bien o para mal, es la noción misma de cultura, su significación social la que está siendo modificada por lo que se produce en y el modo de reproducir de la televisión. (p. 256)

La televisión es entonces el ambiente en el que creció Sergio y, por tanto, en el que forjó su visión y su tacto, como dijera McLuhan (1994, pp. 11, 91, 315-341) sobre la televisión. Este entorno fue completo y definió muchos de sus gustos, intereses y aficiones, y se convirtió también en su exploración constante. En muchos de sus escritos encontramos alusiones a programas televisivos como Alf (Patchett y Fusco, 1986), Out of this World (Fuera de este mundo) (Boni y Booker, 1987), Small Wonder (La pequeña maravilla) (Grossman y Taylor, 1985), Calamar (Mallarino, 1990) y Stranger Things (Duffer y Duffer, 2017) (Uribe-Jongbloed y Roncallo-Dow, 
2018), Black Mirror (Brooker, 2011) (Roncallo-Dow y Mazorra-Correa, 2017), The Leftovers (Lindeloff y Perrota, 2014), The Twilight Zone (La dimensión desconocida) (Serling, 1959) y Twin Peaks (Picos gemelos) (Lynch y Frost, 1990) (Roncallo-Dow y Uribe-Jongbloed, 2019), V (V: La batalla final) (Johnson, 1983), The X-Files (Los archivos X) (Carter, 1994), Thundercats (Akiyama, 1985), Manimal (Boyle y Larson, 1983), Automan (Larson, 1983), toda la gama de CSI (Zuiker y Donnahue, 2000) e, incluso, uno de sus favoritos, Ancient Aliens (Alienígenas ancestrales) (Burns, 2010) (Roncallo-Dow et al., 2016) y recientemente Dejémonos de vainas (Samper Pizano y Romero Pereiro, 1984) (Uribe-Jongbloed y Roncallo-Dow, en prensa). Esta mezcla de reconocidas series televisivas de diversas épocas, tanto en inglés como en español, desde telenovelas hasta realities - como lo demostrase en su presentación sobre las $\mathrm{Ka}(\mathrm{nt})$ dashians - , parece ser un gran ejemplo del tertium datur o tercero incluido (Roncallo-Dow, 2011a, pp. 50-64), a través del cual evitaba caer en las divisiones binarias entre lo local versus lo global, la cultura nacional versus la cultura extranjera y, claramente, la cultura popular versus la cultura elevada. Su mezcla de filosofía con televisión buscaba alejar esa dicotomía clásica entre lo relevante y lo banal, y mostraba que ambos mundos coexisten simultáneamente y que las obras audiovisuales son tan relevantes dentro de ese entorno como los textos de reconocidos pensadores. En esto, claro, seguía la línea de McLuhan de entrelazar los clásicos con los contemporáneos, las series de televisión con las visiones de Byung-Chul Han sobre la sociedad. En este sentido, Sergio (Roncallo-Dow, 2014b) hace exactamente lo mismo que él le endilga a McLuhan, pues asegura que el canadiense
abre muchas puertas sin cerrar ninguna: salta groseramente de Joyce a los noticieros de televisión y, por ejemplo, habla de la cultura grie- ga como si fuera un experto, distorsionando muchos de los textos que ha leído: fracturándolos, haciéndolos hablar, obligándolos —en el más performativo de los sentidos- a decir algo a propósito de $s u$ tiempo. (p. 584)

Es exactamente eso lo que busca hacer Sergio en esa revisión de los productos mediáticos que le interesan: traerlos a relevancia presente, entretejidos, desarmados, de-construidos y re-configurados para hacernos enten- 
der algo sobre el presente. Sus sondas nos han llevado a buscar compaginar al periodista bogotano Juan Ramón Vargas de Dejémonos de vainas y a GuriGuri de la telenovela Calamar con los alienígenas invasores de $V$ y los zombis de The Walking Dead (Darabont, 2010). En este sentido, el ambiente televisivo en el cual existimos lo plasmaba Sergio como realidad a partir de los influjos audiovisuales del que fuera el medio-entorno más importante de nuestra generación: la televisión. De nuevo tomando a McLuhan, Sergio (Roncallo-Dow et al., 2016) nos indicaba la relación fundamental entre la cultura y la producción como dos elementos no separables de nuestro entorno capitalista. Nos recordaba:

Cuando McLuhan sostenía que la cultura era un negocio, pensaba
en el modo en el que la publicidad se había convertido en uno de
los mejores lugares para entender el imaginario de su tiempo. Los
alienígenas eran el mensaje y el negocio: la disfunción se había reve-
lado como algo profundamente funcional, al menos en términos de
rendimiento económico. La cultura pop(ular) se convertiría entonces
en el gran lugar de negocio: alienígenas, monstruos, zombis y demás
seres horripilantes se apoderaron del ecosistema mediático. Al ser
parte del imaginario colectivo, la disfunción revertía en su opuesto e
impulsaba un imaginario colectivo que, como ya vimos, llega hasta
nuestros días. (p. 34)

El medio es el mensaje y, simultáneamente, el negocio. Esta idea del rendimiento económico de ese entorno mediático en el que crecimos también lo discute Sergio con la apropiación de la nostalgia. En la reflexión que plantea sobre Stranger Things (Uribe-Jongbloed y Roncallo-Dow, 2018), nos deja claro este proceso de apropiación económica de nuestra infancia:

Nuestra nostalgia está construida sobre los medios de transmisión nacional, los cuales ofrecían una variedad limitada cuando no inexistente. La llegada de Internet en los 90 tardíos nos permitió explorar el mundo y buscar los recuerdos ya desvanecidos de los 80 en la forma de juguetes viejos o libros olvidados de nuestra niñez. Esta recuperación de una infancia perdida es, quisiéramos argumentar, lo que hace que Stranger Things sea tan exitoso en Colombia. Aunque distante de nuestras experiencias cotidianas de los 80 -ninguno de nosotros comió un Eggo al desayuno, por ejemplo- nos permitió repensar nuestro pasado e idealizarlo en una forma de consumo: juegos de mesa, música, juguetes y la idea de un mundo que era más fácil de comprender. (p. 52) 
Si juzgamos por la cantidad de memorabilia que reposaba en los anaqueles de Sergio y alrededor de su estudio, vemos que esa dirección hacia el consumo de nuestros recuerdos era una búsqueda constante, que se acercaba también a la aparente simplicidad de las tramas de Calamar o Dejémonos de vainas. La inocencia televisiva llena de paramilitares bondadosos que jamás herían a nadie —en el caso de The A-Team (Los magnificos) (Cannel y Lupo, 1983) — y obreros verborreicos —en Don Chinche (Sánchez, 1982) - . Este punto de intersticio de la televisión colombiana, que hibridaba las series extranjeras con comedias y melodramas locales, era evidencia y fuente de nuestra cultura, y hacía que simultáneamente fueran nuestras las historias macondianas de Caballo viejo que "fue capaz de poner en televisión la magia del país que conecta al otro resto con el mundo-caribe, que es la gracia de las novelas garciamarquianas" (Martín-Barbero en Rincón, 2016, p. 35) y las aventuras de dobles de acción cobrando fianzas en The Fall Guy (Profesión peligro) (Larson, 1981) en Los Ángeles (Roncallo-Dow et al., 2016, p. 153). Esta hibridación entre el influjo norteamericano y europeo se ensamblaba con la producción local y las telenovelas de toda Latinoamérica, entre el humor de Benny Hill (Hill, 1969) y aquel de El Chavo del 8 (Gómez Bolaños, 1973). Esta era una experiencia que daba cuenta del tertium datur en el que éramos simultáneamente modernos y pre-modernos, urbanos y rurales, colonizados culturalmente y creadores de cultura nacional. Por eso, Sergio nos señala:

\begin{abstract}
Solo en la medida en que reconozcamos nuestra esencia híbrida y las condiciones particulares de modernización e inserción en la dinámica de las industrias culturales, de la cultura visual, luego multimedial, comprenderemos por qué en nuestras ciudades hay culturas nuevas en las cuales los medios no son simplemente canales de transmisión de una cultura ya hecha sino de gestación misma de las nuevas formas culturales en tanto la tecnología de comunicación/cultura se ha convertido en el canal de interacción e hibridación con las formas locales del resto del mundo. (Roncallo-Dow, 2019, p. 75)
\end{abstract}

Esa hibridación de la que nos habló García-Canclini (2000) remite a que somos una interacción entre esas expresiones de nuestro audiovisual con aquellas del audiovisual extranjero. Que los márgenes o las fronteras que antes supuestamente encapsulaban nuestra identidad cada vez son menos claras y que, por tanto, "hoy en día sabemos que la historia de nuestro 
continente es la historia de luchas, enfrentamientos e hibridaciones. En la hibridación está nuestra especificidad” (Roncallo-Dow, 2019, p. 75).

Uno de esos ejemplos que también marcó un hito para Sergio fue MTV (Roncallo-Dow et al., 2016, pp. 78-94). Ahí encontró el fulcro de su amor por el videoclip y su pasión eterna de rockero. Pero para abordar este aspecto es necesario que entendamos profundamente la relación entre Sergio y el rock.

\section{El filósofo como rock star}

Desde los años sesenta, el rock se convirtió en el himno de las masas y se desarrolló no solo como género musical, sino como portavoz de una cultura del cambio, creciente y cada vez menos ignorada. (Fierro Valbuena y Roncallo-Dow, 2014, p. 214)

Como buen hijo de la fría Bogotá de finales del siglo XX, Sergio creció como un melómano empedernido del rock. Alguien para quien la música se convirtió en centro de atención y en una pasión que trascendió lo estético para convertirse en una forma de vida, espacio de creación, una voz de apoyo a sus ideas y, por supuesto, un objeto de estudio y reflexión importante para comprender fenómenos tardomodernos, como él mismo habría acotado.

El rock acompañó su trayectoria — comola acuñó Bourdieu (1988) — de vida, y podría afirmarse que fue determinante en su desarrollo como intelectual irreverente. El rock estuvo ahí desde su infancia, lo apaciguó ante la partida temprana de su padre y le permitió expresarse por medio de licks de guitarra tan intensos y fuertes como sus ideas, desde los tiempos de estudiante hasta los de maestro. Formó parte de varias agrupaciones, entre ellas, Los Telebolitos, Los Dobermann, Los Pussylánimes y Pollito CHICKEN (los nombramos porque no nos habría perdonado su omisión).

A través del rock, Sergio encontró una manera particular de evidenciar ese pensamiento filosófico oculto en lo cotidiano. Ese pensamiento que cuestiona, interpreta e interpela el mundo que nos rodea y que está 
ahí, muchas veces dicho en rima y con cuatro acordes. Así, su trabajo académico está lleno de epígrafes rockeros, a través de los cuales introducía el tema central del debate que quería proponer. Fue precisamente esta habilidad particular la que le permitió utilizar Fear of the Dark, de Iron Maiden (1992), y plantear que "I have a phobia that someone's always there" da cuenta de aquello a lo que Hans Blumenberg apuntaba con el concepto de distancia, afirmando que

\begin{abstract}
la necesidad de domesticar el entorno a través de la continua mitificación resultaba una tarea ineludible en el momento de intentar ocupar el hombre su propio lugar en el mundo: casi como si la salida de la selva tupida y frondosa hacia la descubierta llanura probara la desnudez propia de un ser indefenso y colmado de temores. (RoncalloDow, 2008, p. 61)
\end{abstract}

De igual manera, emerge Welcome to the Jungle, de Guns N' Roses (1987), que le permitió introducir una revisión al trabajo de Marshall McLuhan, para poder presentar cómo este, más allá de proponer una teoría de los medios y de la comunicación, había formulado una forma otra de ver el mundo (Roncallo-Dow, 2011b); de comprender el mundo a partir de las herramientas que generamos y que posteriormente se convierten en modeladoras de nuestra vida, como si se tratase de un mundo con una gran cantidad de opciones disponibles para sus habitantes, o una jungla que da la bienvenida a sus visitantes y ofrece todo lo que estos puedan desear.
La idea de una cosmovisión mcluhaniana lo que realmente encierra es la necesidad de pensar la complejización del sistema técnico en la era de las telecomunicaciones, y cómo desde la imbricación de los varios sistemas que desembocan en ese todo al que llamamos mundo, lo que se despliega son toda suerte de cambios que afectan, precisamente, el modo en el que el sujeto comprende y se relaciona con su entorno. (p. 124)

La incertidumbre frente al futuro, como punto de partida de narrativas gráficas, encontró una ventana de exposición en el trabajo de Sergio, en un ejercicio por crear unas tipologías de distopía y la manera como estas se hacían presentes en el cómic nacional (Roncallo-Dow et al., 2019), específicamente en aquellas historias que contaban con la ciudad de Bogotá como escenario o protagonista de estas; narraciones bastante dicientes de 
la percepción de nuestra realidad. Historias que reflejan, en buena medida, incertidumbre y desesperanza sobre el devenir futuro. Historias apocalípticas, tristes, violentas, caóticas, resultado propio de un presente igualmente violento en diferentes formas. Esa incertidumbre y distopía no pudieron ser mejor introducidas que con un epígrafe que da cuenta del coro de una canción de REM (1987) "It's the end of the world as we know it".

Por otra parte, en El aura ya no existe para el rock presenta Sergio (Roncallo-Dow, 2006) la emergencia del rock y su configuración como producto contra-cultural que significó a su vez la emergencia del sujeto tardomoderno joven, para quien la música rock representa un "escape a la frialdad de los cuerpos y [... única respuesta a la búsqueda desenfrenada de la singularidad” (p. 114). En la obra, Sergio reflexiona en torno a su valor como elemento expresivo y cómo va siendo apropiado por las dinámicas propias del mercado hasta convertirlo en un producto cultural de consumo masivo en el que la singularidad e irrepetibilidad propia del génesis del rock se diluyó con el advenimiento de los media; "el aura ya no existe para el rock; la individualidad le es ajena” (p. 116).

Desde 2006 se aproxima a la pregunta en torno a la identidad o las identidades que emergen con el sujeto joven tardomoderno. Un sujeto que encuentra en la música y, particularmente en el rock, un espacio para la configuración de un nosotros joven que, a su vez, se reconoce en su otredad. Así pues, el rock se convirtió en un dispositivo que permitió salir de esa frialdad (del conservador contexto de posguerra en el que emerge) a través de manifestaciones estéticas que se vuelven cuerpo, experiencia y, por ende, forma de vida.

En este punto, asume la mirada de los estudios culturales como una perspectiva que ofrece elementos importantes para comprender el valor del rock inscrito en un marco cultural particular, que le permite mantener elementos de lo masivo, de lo mediático y, a la vez, adaptarse a contextos y asumirse como producción cultural en cada uno de estos. Por lo anterior, también asumió una posición crítica frente a la manera, quizá taxonómica, como algunos culturalistas de la década de los noventa decidieron asumir 
la relación entre jóvenes y música, anotando que "es mucho más que sonido: la música es visceral; es una forma de vida, en especial, para los jóvenes quienes la hacen su vida" (Fierro Valbuena y Roncallo-Dow, 2014, p. 215).

Por otro lado, Sergio toma la propuesta hecha por De Garay (1989) frente al rock como un ejemplo en el funcionamiento de un sistema, a fin de manifestar que habría dos enfoques posibles para comprender este planteamiento. El primero de ellos, desde la perspectiva del rock como elemento liberador —en referencia a Rancière (Roncallo-Dow, 2011a, pp. 348-352) —, como un modo de des-sujeción frente a un régimen policivo. El segundo se formula como un metarrelato de un nosotros que intenta separarse del sistema en que se inscribe, pero que no puede sacudirse de esta sujeción y termina siendo absorbido por este, como si se tratase del vacuum monster de la película Yellow Submarine (Dunning, 1968).

Por último, quisiéramos señalar el particular interés que mostró Sergio en el videoclip como manifestación audiovisual del rock tardío. En principio, evidencia una relación quizá incómoda, pues el video como lenguaje audiovisual está pensado para mostrar, para cumplir una función icónica que eventualmente tiene unos matices narrativos, pero que en esencia cumple una función de registro. Por otro lado, el arte, y la música particularmente, cuentan cosas (Roncallo-Dow, 2013). A pesar de ello, en su acercamiento a la nostalgia como elemento de interés epistemológico, encontró Sergio una fascinación en esa relación que emerge y se consolida desde la década de los ochenta entre música y videoclip. Una relación que transformó las formas de hacer música, pues, además, implicaba la reflexión en torno a la performance mediática, más allá del concierto. Es decir, que se sumerge en eso que Illescas Martínez (2015) denomina la dictadura del videoclip.

A partir de lo anterior, plantea Sergio una relación interesante entre videoclip y música, en la que, aun cuando obedecen a orígenes y naturalezas distintas, desarrollaron una sinergia que deviene en la configuración de toda una estética audiovisual que rige la producción musical del rock en tanto producto cultural de consumo masivo. Esto sucede desde la década de los ochenta y da paso a la reconfiguración simbólica que se genera en 
esa relación entre video y música, en la que se asoman narrativas que convergen, pero que a su vez trascienden la relación obvia entre ambos, y así da a entender "la idea de que música e imagen constituyen dos textos diversos que se yuxtaponen y forman uno tercero" (Roncallo-Dow y UribeJongbloed, 2017b, p. 81).

En la misma lógica, esa relación estrecha entre videoclip y rock aparece de manera brillante en el texto de Roncallo-Dow et al. (2016) que sirve como elemento conector entre Barthes y la constitución del mito, hasta llegar a McLuhan y la ecología mediática, atravesando el mundo de la semiótica y la configuración de elementos sígnicos. Así pues, el videoclip, en relación estrecha con el rock, funge como dispositivo exegético de las funciones semióticas.

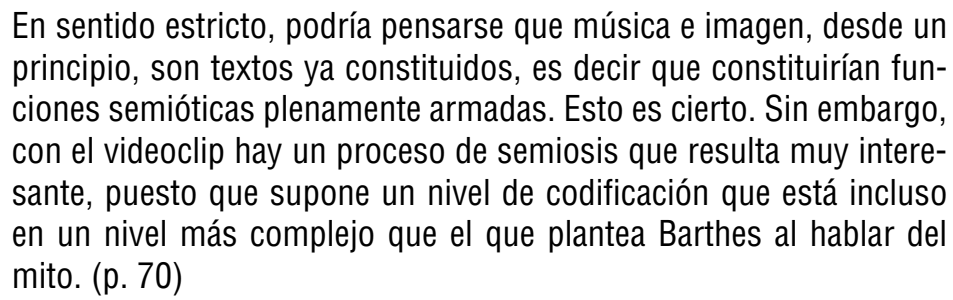

Finalmente, la preocupación en torno al rock por parte de Sergio (Roncallo-Dow et al., en prensa) no quedó del todo inconclusa. Se centró en el último año en la edición de un volumen en el que convocó académicos de diferentes partes del país y de Latinoamérica a reflexionar en torno al lugar del rock en la sociedad actual y su valor en sentido político, cultural y comunicacional.

Puede ser que haya faltado tiempo y más música, pero su legado queda en textos de profunda reflexión que seguramente impactarán más adelante diferentes campos de conocimiento. De igual manera, y en absoluta congruencia con su pasión por el rock, no solo dejó grabaciones de su música, sino también el recuerdo de un joven intelectual que con rostro adusto, saco y corbata, pero con tenis y haciendo el famoso gesto de rock n'roll pesado, nos dijo en algún momento: el sur es el mensaje. 


\title{
El habitar en los mundos virtuales
}

\author{
Watching all our friend's fall \\ In and Out of Old Paul's \\ This is my idea of fun \\ Playing video games \\ Video Games, Lana del Rey (2011)
}

Así pues, en la música, la TV y la nostalgia, Sergio reconoció un arena, un ecosistema mediático, en que se negociaban significados, ideologías e identidades. Sin embargo, si en un sentido parte de su mirada se fijaba en el pasado como escenario de hibridación y contestación, sus ideas jamás perdieron de vista el presente y, en muchos casos, lo inquietaban las tendencias que veía proyectarse hacia el futuro. Si bien en sus colecciones también aparecían íconos ya casi históricos de los videojuegos (por años un póster de Asteroids, el juego para Atari, adornó su oficina y el nombre de una de las bandas en las que participó era un gran juego clásico, el Telebolito), sus inquietudes sobre el entorno digital en el que cada vez nos vemos más inmersos siempre miraban hacia adelante. Mientras observaba el re-configurarse de nuestro sensorium, desde Benjamin (Roncallo-Dow, $2011 \mathrm{a}, \mathrm{p} .103$, n. 63), Sergio seguía buscando incomodar a quienes por momentos nos enfocábamos en contemplar esta evolución, haciendo hincapié en la importancia de repensar las posibilidades y los peligros que se esconden tras las nuevas posibilidades de nuestro entorno.

Un excelente ejemplo de la resistencia roncalliana al testimonio simple y descriptivo de la configuración de un medio es su examen de YouTube (Roncallo-Dow et al., 2016, cap. 3). En esta reflexión, Sergio nos invita a alejarnos de una evaluación superficial de las posibilidades técnicas de la página de internet e ir más allá. En sus palabras:

No se trata de trazar, entonces, una reflexión sobre la relación videointernet que se agote en las posibilidades técnicas y en los modos de manipulación de lo audiovisual-visible; son los modos de ver y los entornos que se abren los que permiten echar a andar una reflexión 
en la que la fractura de los códigos dominantes vaya más allá de la dificultad formal o de lo "novedoso" de la intervención. (p. 108)

¿Cuál es, entonces, la reflexión a la que nos invita en este caso? Sergio ve en YouTube un elemento clave en su propuesta sobre los medios contemporáneos; ve "un nuevo hábitat, lejano de la naturaleza y desvinculado de la tangibilidad" (p. 108). En este hábitat, Sergio ve un espacio para re-configurar lo audiovisual, para experimentar con ello nuevas formas de crear y significar. YouTube no es el producto de un autor creador, ni una simple librería de obras, es un espacio para la re-combinación, el re-mix (la re-mezcla) o la re-semantización (Roncallo-Dow, 2016). En lugar de ver en YouTube la tumba del aura, Sergio propone que es simplemente un lugar donde el aura se transforma (Roncallo-Dow et al., 2016, pp. 109-111).

Esta visión del medio como hábitat y de las potencialidades que esto implica también la vio Sergio en los videojuegos y los mundos virtuales que hoy por hoy siguen evolucionando (Roncallo-Dow et al., 2013). En este caso, Sergio veía la clara transformación de la figura del autor y del aura. Con respecto a estos juegos, Sergio y sus colegas se preguntan quién es el autor en un universo creado, recreado $y$, sobre todo, habitado por un amplio elenco de personas. Esta cuestión puede parecer trivial, o simplemente retórica, y en la actualidad pareciéramos vernos forzados a responderla a la luz de leyes de derechos de autor que fueron creadas en otros contextos. Sin embargo, para Sergio y sus colegas, llega a convertirse en la proverbial piedra en el zapato con la que nos obligaban a pensar los cambios que se están dando, y que se tienen que dar, en un mundo donde las narrativas son cada vez menos producto de una mente, que se presume originaria, y cada vez más una experiencia de quienes habitan estos espacios cargados de potencialidades.

Sergio y sus colegas (Roncallo-Dow et al., 2013) nos recuerdan lo artificial que resulta la idea del autor romántico del que se desprende toda energía poiética y que materializa del éter la obra de arte. En su texto sobre la importancia de replantear los derechos de autor en los mundos virtuales, los autores traen al presente las reflexiones sobre el rol semiótico de la 
audiencia propuestas por Barthes y de la función real de la figura del autor en la semiosis propuesta por Foucault (1986). En esa reflexión, se propone la idea de que repensar al autor no como individuo sino como función permite concebir a una comunidad como la fuente de una narrativa dinámica, de la evolución y transformación de un espacio que se habita. Resulta particularmente evocador la forma en que en esta reflexión Sergio y sus colegas traen a colación el origen del habitar, que ya reconocemos como un tema constante en las ideas de Sergio citando a Heidegger, y que ya habíamos mencionado. En este caso, el énfasis en habitar es tomado del ensayo Construir, habitar y pensar de Heidegger (Roncallo-Dow et al., 2013, p. 3), en el que el filósofo reflexiona sobre lo esencial para el humano que es cultivar y cuidar de la tierra cuando se habita.

Así pues, Sergio llegó a ver los videojuegos como espacios abiertos que encuentran su origen en el trabajo de unos — autor desarrollador-, pero que se realiza y se cultiva en las manos de quienes llegan a habitarlos - autor usuario - - Si todas estas manos habitan el mismo espacio, todas se pueden encapsular en la función-autor. En este espacio, la capacidad poiética no recae en un demiurgo genio y el aura no encierra su valor ritual tras las barreras a las que solo unos pocos afortunados pueden acceder. Allí el aura se transforma y encuentra el potencial expositivo que Benjamin había percibido ya en el amanecer de los medios masivos.

La inminencia del cambio y la tensión entre sus potenciales conclusiones quizá eran las razones por las que Sergio conectaba y resonaba intensamente con las ideas de Benjamin (1989). Si, por un lado, leer a Benjamin es recordar la lucha latente entre las posibilidades del aura de ser coaccionada en su ritualidad para apoyar la hegemonía opresora o de romper ese yugo y amplificar a través de la reproducción la democratización del arte, por otro, leer a Sergio es recordar que en la obra también está latente la posibilidad de acallar todas las voces menos la del autor creador o la de hacer resonar el timbre del autor desarrollador y, por qué no, la de una multitud de autores jugadores. Sergio nos dejaba así, no tanto una respuesta, sino una provocación para que viéramos, como decía León-O de los Thundercats, "más allá de lo evidente". 


\section{Última sonda}

Objects in the rearview mirror may appear closer than they are.

Meatloaf (1994)

Sergio fue siempre un jugador en equipo. Le encantaba compartir su conocimiento en clases, en presentaciones y en las discusiones personales en su hogar. Su obra incluye gran cantidad de colaboraciones, pues, para él, basado en Heidegger, el ser no es solo un ser-ahí (da-sein), sino un ser-ahícon otros (mit-dasein) (Roncallo-Dow, 2019). Por esto, la obra de Sergio muestra a su vez una noción de construcción colectiva que le parecía tan valiosa y tan central en el proceso mismo humano que lo llevaba a rechazar muchas aproximaciones contemporáneas que presentaban a individuos como creadores únicos y acuñadores de términos revolucionarios. De este modo, evidenciaba que muchas de estas palabras novedosas no son más que re-mezclas o re-encauches de cosas que ya venían sucediendo siempre en el entramado mediático, solo que por modas o un cierto resurgimiento de sus evidencias vuelven a quedar en boca de todos, como es el caso de la convergencia (Arango-Forero et al., 2016).

La telenovela, el rock, el videoclip, los videojuegos y las figuras coleccionables eran todas parte de su entorno mediático, se vinculaban constantemente a su labor cotidiana y le daban siempre un espacio a la cultura pop en su producción académica. Su felicidad por escarbar entre estas manifestaciones para complementar su imagen del ambiente comunicativo y ayudarnos a re-pensar (así, con guion, como tanto le gustaba) nuestro lugar en el presente. Sus búsquedas se respaldaban en la noción mcluhaniana que reconocía que "la cultura popular y el entretenimiento cedieron ante la técnica tan fácilmente como hicieron los sentimientos más nobles y las imágenes más refinadas del arte clásico y la arquitectura” (E. McLuhan, 2015, p. 1000). Estudiar de ese modo la técnica era estudiar la cultura, y viceversa, pues "la idea misma de cultura es parte de esa tecno-logía que ha des-velado el mundo frente al hombre” (Roncallo-Dow, 2011a, p. 48). En ese sentido, Sergio se oponía radicalmente a pensar una separación de estos dos elementos en consideración a que "la paulatina deshumanización 
de la idea de la técnica como algo que se opone a la cultura ha llevado a su in-comprensión como elemento fundamental para entender los modos de interacción y cambio social" (p. 26).

Esa era, siempre, en esencia su provocación, su sonda. Una última referencia suya a McLuhan que queremos traer aquí para mostrar su íntima conexión con su maestro se encuentra al reconocer el arte como un antimedio, capaz de develarnos el intríngulis que es el medio mismo:

\begin{abstract}
A mi juicio, la idea del ambiente puede interpretarse como el gran punto de llegada del apotegma [el medio es el mensaje] y su entretejimiento con el arte pone en evidencia lo impensado de la técnica en términos de la estrecha relación que tiene con el modo mismo en el que el hombre se empodera de su entorno; en otras palabras, al sostener que el medio es el mensaje, McLuhan mostraba cómo pocas veces somos conscientes del propio zeitgeist y cómo nuestra relación con la totalidad es un punto que debe ser evidenciado desde los márgenes. (Roncallo-Dow, 2011a, p. 342)
\end{abstract}

Esos márgenes, que podían incluir disímiles compañeros como el rock en español, las series animadas, el "tiburulpo" - traducción horrible de Sharktopus (O’Brien, 2010) —, los videojuegos, el arte transgénico o el reality de las $\mathrm{Ka}(\mathrm{nt})$ dashians, eran una forma de señalarnos y evidenciarnos nuestro mundo mediático, nuestro ambiente contemporáneo.

Vivimos a través de las imágenes que ofrece el espejo retrovisor [...] inmersos en un ambiente que nos modela y que no percibimos, que nos hace ser lo que somos y que actúa replegado como un fondo que estructura lo que, con Husserl, llamaríamos el mundo-de-la-vida. (Roncallo-Dow, 2011a, pp. 337-338)

Ese mundo-de-la-vida en el cual Sergio estuvo-con nosotros (mitdasein) era el mundo híbrido de la Colombia de 1980 a 2020.

En su discurso de inauguración del Doctorado en Comunicación de la Universidad de La Sabana nos planteó lo que significaba, precisamente, estudiar la comunicación desde este otro lugar. Su legado es fuerte, por lo amplio de las preguntas que nos lanzó sobre esa realidad en la que vivimos. Nos queda seguir su llamado para continuar comprendiéndonos desde otros anclajes, con otras perspectivas. 
Creo que la idea de Heidegger según la cual el hombre habita poéticamente el mundo hay que re-pensarla como un habitar que es más bien tecnológico pero ese habitar es múltiple, situado, específico. El Sur es el mensaje 0, como dicen Los Reyes Latinos: latinos somos y latinos seremos. (Roncallo-Dow, 2019, p. 82)

Nosotros, quienes aún estamos aquí (dasein), aprendemos de Sergio buscando mirar, como él, más allá del espejo retrovisor.

\section{Referencias}

Arango-Forero, G., Roncallo-Dow, S. \& Uribe-Jongbloed, E. (2016). Rethinking convergence: A new word to describe an old idea. En A. Lugmayr y C. D. dal Zotto (Eds.), Media convergence handbook. Vol. 1: Journalism, broadcasting, and social media aspects of convergence. (pp. 17-28). Springer.https://doi.org/10.1007/978-3-642-54484-2_2

Benjamin, W. (1989). La obra de arte en la época de su reproductibilidad técnica. En Discursos interrumpidos (vol. 1, pp. 15-57). Taurus.

Bourdieu, P. (1988). Homo academicus. Siglo XXI.

Fierro Valbuena, A. y Roncallo-Dow, S. (2014). Entre porosidad y blindaje: el devenir de la identidad. Discusiones Filosóficas, 15(24), 201 219. http://www.scielo.org.co/pdf/difil/v15n24/v15n24a11.pdf

Foucault, M. (1986). What is an author? En P. Rabinow (Ed.), The Foucault reader. (pp. 141-160). Pantheon.

Garay, A. de. (1989). Prolegómenos al estudio de la cultura rock. Estudios sobre las Culturas Contemporáneas, 2(6), 117-135. https://www. redalyc.org/pdf/316/31620605.pdf

García-Canclini, N. (2000). Culturas híbridas: estrategias para entrar y salir de la modernidad. Grijalbo.

Guns N’ Roses. (1987). Welcome to the Jungle. En Appetite for Destruction $[\mathrm{CD}]$. Geffen. 
Illescas Martínez, J. (2015). La dictadura del videoclip: industria musical y sueños prefabricados. El viejo topo.

Iron Maiden. (1992). Fear of the Dark. En Fear of the Dark [CD]. EMI Epic.

Martín-Barbero, J. (2010). De los medios a las mediaciones: comunicación, cultura y hegemonía. Anthropos.

Meatloaf. (1994). Objects in the Rearview Mirror May Appear Closer than They Are. En Bat Out of Hell II: Back into Hell [CD]. MCA.

McLuhan, E. (2015). La teoría de la comunicación de Marshall McLuhan: el butronero. Palabra Clave, 18(4), 979-1007. https://doi. org/10.5294/pacla.2015.18.4.2

McLuhan, M. (2015). Inédito. La marca editora.

McLuhan, M. (1994). Comprender los medios de comunicación: las extensiones del ser humano. Paidós.

Reed, L. (1992). What's Good. En Magic and Loss [CD]. Sire.

REM. (1987). It's the End of the World as We Know It (And I Feel Fine). En Document [CD]. I.R.S.

Rey, L. del. (2011). Video Games. En Born to Die [CD]. Polydor Vertigo.

Rincón, O. (2016). Jesús Martín-Barbero: de una televisión y un cine que supieron meter país, hacer memoria y contarnos su historia. Cuadernos de Cine Colombiano, 25, 28-45.

Roncallo-Dow, S. (2006). El aura ya no existe para el rock. Revista La Tadeo, 7A(72), 109-118. https://revistas.utadeo.edu.co/index.php/ $\mathrm{RLT} /$ article/view/529

Roncallo-Dow, S. (2008). El juego de la distancia: entre la significatividad y la recepción: un viaje por los Prometeos de Blumenberg. Universi- 
tas Philosophica, 25(51), 59-83. https://revistas.javeriana.edu.co/ index.php/vniphilosophica/article/view/11191

Roncallo-Dow, S. (2011a). Más allá del espejo retrovisor: la noción de medio en Marshall McLuhan. Pontificia Universidad Javeriana.

Roncallo-Dow, S. (2011b). Medios, antimedios, sondas y clichés: revisitando a Marshall McLuhan, el explorador. Signo y Pensamiento, 30(59), 121-138. https://revistas.javeriana.edu.co/index.php/ signoypensamiento/article/view/2437

Roncallo-Dow, S. (2013). Video, videoarte, iconoclasmo. Cuadernos de Música, Artes Visuales y Artes Escénicas, 8(1), 103-125. https://www. redalyc.org/pdf/2970/297027568006.pdf

Roncallo-Dow, S. (2014a). Habitar: revisitando el medio mcluhaniano. En E. A. Vizer (Ed.), Lo que McLuhan no predijo. (pp. 99-116). La Crujía.

Roncallo-Dow, S. (2014b). Marshall Mc Luhan: el medio (aún) es el mensaje 50 años después de comprender los medios. Palabra Clave, 17(3), 582-588. https://doi.org/10.5294/pacla.2014.17.3.1

Roncallo-Dow, S. (2016). Confused Travolta o el placer de lo simple. Palabra Clave, 19(1), 8-14.https://doi.org/10.5294/pacla.2016.19.1.1

Roncallo-Dow, S. (2019). The south is the message: Media ecology reception and perspectives in Latin America. En Á. Preciado Hoyos (Ed.). Media ecology: A field of study. (pp. 71-88). Universidad de La Sabana.

Roncallo-Dow, S. y Mazorra-Correa, D. (2017). "Nosedive”: la pornografía suicida de Black Mirror. En J. Martínez-Lucena y J. Barraycoa (Eds.), Black mirror: porvenir y tecnología. (pp. 181-196). UOC. 
Roncallo-Dow, S. y Otero Herrera, N. (2016). Superman: el espejo de la identidad recuperada y nunca encontrada. En S. Roncallo-Dow, E. Uribe-Jongbloed y E. Gutiérrez (Eds.), Identidades, héroes y discursos en la modernidad tardía. (pp. 255-272). Universidad de La Sabana.

Roncallo-Dow, S. y Uribe-Jongbloed, E. (2017a). Abstract numbers close at hand: The tactile, numbers and money in Mcluhan's works. TOPIA: Canadian Journal of Cultural Studies, 38, 25-45. https:// doi. org/10.3138/topia.38.25

Roncallo-Dow, S. y Uribe-Jongbloed, E. (2017b). La estética de los videoclips: propuesta metodológica para la caracterización de los productos audiovisuales musicales. Cuadernos de Música, Artes Visuales y Artes Escénicas, 12(1),79-109. https://doi.org/10.11144/ Javeriana.mavae12-1.evpm

Roncallo-Dow, S. y Uribe-Jongbloed, E. (2019). The Leftovers: No More Tears o sobre la disolución del nosotros. En J. Martínez-Lucena, A. González de León Berini y S. Abbate (Eds.), Control social e imaginarios en las teleseries actuales. (pp. 155-166). UOC.

Roncallo-Dow, S., Aguilar-Rodríguez, D. y Uribe-Jongbloed, E. (Eds.). (en prensa). Después del final: teorías, historias y nostalgias del rock. Universidad de La Sabana.

Roncallo-Dow, S., Aguilar-Rodríguez, D. y Uribe-Jongbloed, E. (2019). La Bogotá distópica: los cómics sobre una ciudad en caos. Co-herencia: revista de humanidades, 16(30), 27-56. https://doi.org/10.17230/ co-herencia.16.30.2

Roncallo-Dow, S., Goyeneche, E. y Uribe-Jongbloed, E. (2016). Volver a los clásicos: teorías de la comunicación y cultura pop. Universidad de La Sabana. 
Roncallo-Dow, S., Uribe-Jongbloed, E., Barker, K. y Scholz, T. (2013). Authorship in virtual worlds: Author's death to rights revival? Journal of Virtual Worlds Research, 6(3). https://doi.org/10.4101/ jvwr.v6i3.6361

Uribe-Jongbloed, E. y Roncallo-Dow, S. (en prensa). Dejémonos de vainas, ¡sí? YouTube como memoria y archivo televisivo colombiano. Universidad Externado de Colombia.

Uribe-Jongbloed, E. \& Roncallo-Dow, S. (2018). Stranger Things and our memories of Colombian TV in the late eighties: Bringing back Alf, V.I.C.I, Evie and Guri-Guri. En K. J. Wetmore (Ed.), Uncovering Stranger Things: Essays on eighties nostalgia, cynicism, and innocence in the series. (pp. 49-59). McFarland. 